\title{
The effects of depressive symptoms on academic achievement and adjustment to college
}

Ivanka Živčić-Bećirević, Sanja Smojver-Ažić, Tamara Martinac Dorčić

University of Rijeka, Faculty of Humanities and Social Sciences, Department of Psychology, Rijeka, Croatia

\section{Introduction}

The prevalence of depression among university students is pretty high with increase in recent years (Eisenberg et al., 2017). Student mental health problems are strong negative predictors of academic outcomes (Beiter et al., 2015).

\section{Goal}

The main goal of this prospective study is to test the effects of depression on student academic achievement and adjustment to college.

\section{Method}

The representative sample of 492 undergraduate students (60\% females) from various study programmes completed Student Adaptation to College Questionnaire (SACQ, Baker \& Siryk, 1999) and Beck Depression Inventory (BDI-II, Beck, Steer \& Brown, 2011). Students are followed during three academic years. Academic achievement was measured by cumulative grade point average (GPA), number of academic credit points (ECTS) and student efficacy status after 3 years (finishing undergraduate study on time, repeating a year, dropped-out).
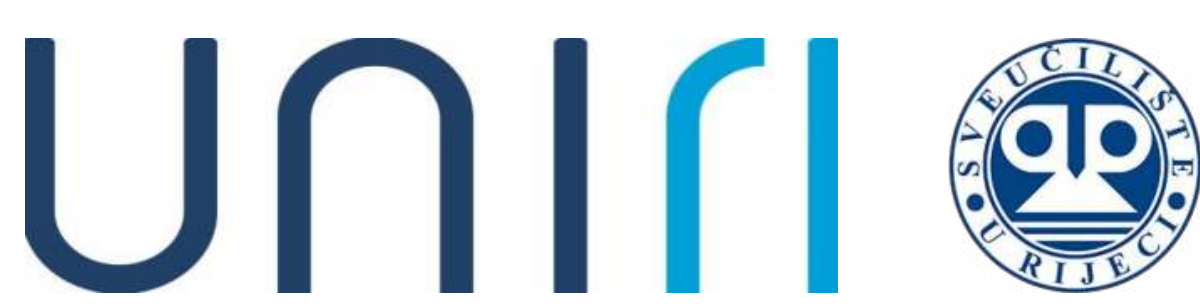

This work has been fully supported by the University of Rijeka under the project number 1155 .

\section{Results}

The results showed that $23 \%$ of all the freshmen have increased level of depressive symptoms (BDI>11 according to Croatian norms).

Figure 1. Percentage of students with increased depressive symptoms, regarding to gender and residential status

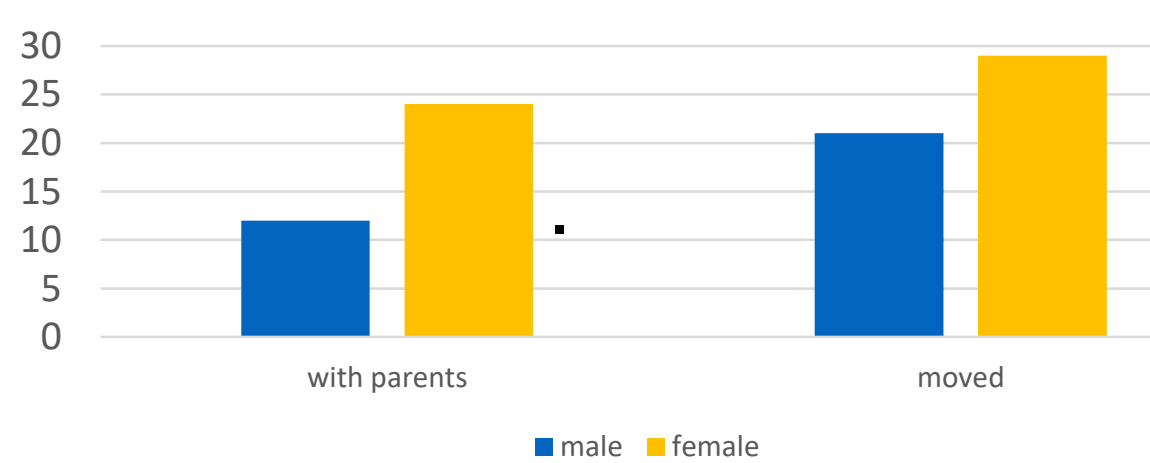

The level of depressive symptoms was not correlated with GPA, but it was negatively correlated with the number of ECTS achieved at the 3rd year, indicating poor efficiency of depressed students. The students with more depressive symptoms also had worse academic, emotional and social adjustment at the beginning and at the $3^{\text {rd }}$ year (Table 1 ).

Table 1. Correlations Between Depressive Symptoms and Student's GPA and Number of Credits Achieved During Three Years of College

\begin{tabular}{|c|c|c|}
\hline & BDI $1^{\text {st }}$ year & BDI $3^{\text {rd }}$ year \\
\hline GPA $3^{\text {rd }}$ year & .09 & -.05 \\
\hline Credits $3^{\text {rd }}$ year & .01 & $-.14^{*}$ \\
\hline \multicolumn{3}{|c|}{ Adjustment $1^{\text {st }}$ year } \\
\hline Academic & $-.42^{\star *}$ & $-.22^{\star \star}$ \\
\hline Emotional & $-.70^{\star *}$ & $-.40^{\star \star}$ \\
\hline Social & $-.41^{* \star}$ & $-.16^{\star}$ \\
\hline \multicolumn{3}{|c|}{ Adjustment $3^{\text {rd }}$ year } \\
\hline Academic & $-.24^{* *}$ & $-.47^{\star *}$ \\
\hline Emotional & $-.46^{* *}$ & $-.66^{* *}$ \\
\hline Social & $-.29^{* *}$ & $-.49^{* *}$ \\
\hline
\end{tabular}

The students who dropped-out from college do not differ from those who stayed in their initial level of depression, but they have increased level of depressive symptoms on the $2^{\text {nd }}$ year.
A significantly higher percentage of students with a high level of depression at the $2^{\text {nd }}$ year dropped out from college or repeated a year, comparing to those with a low level of depressive symptoms (Figure 2).

Figure 2. Relative Frequency of Students Regarding their Level of Depressive Symptoms and their Academic Efficacy after 3 Years in College
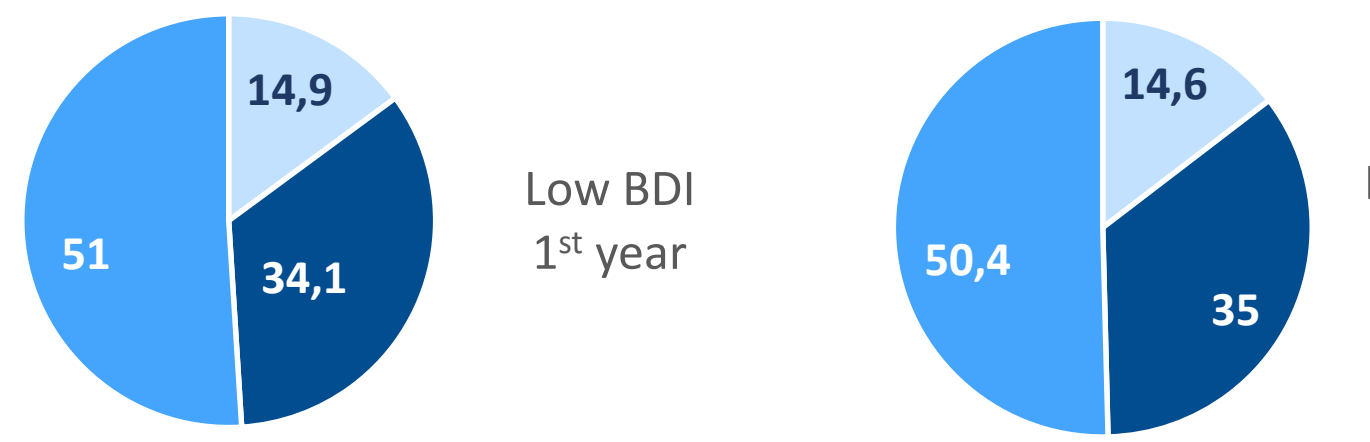

Increased BDI

$1^{\text {st }}$ year

dropped out
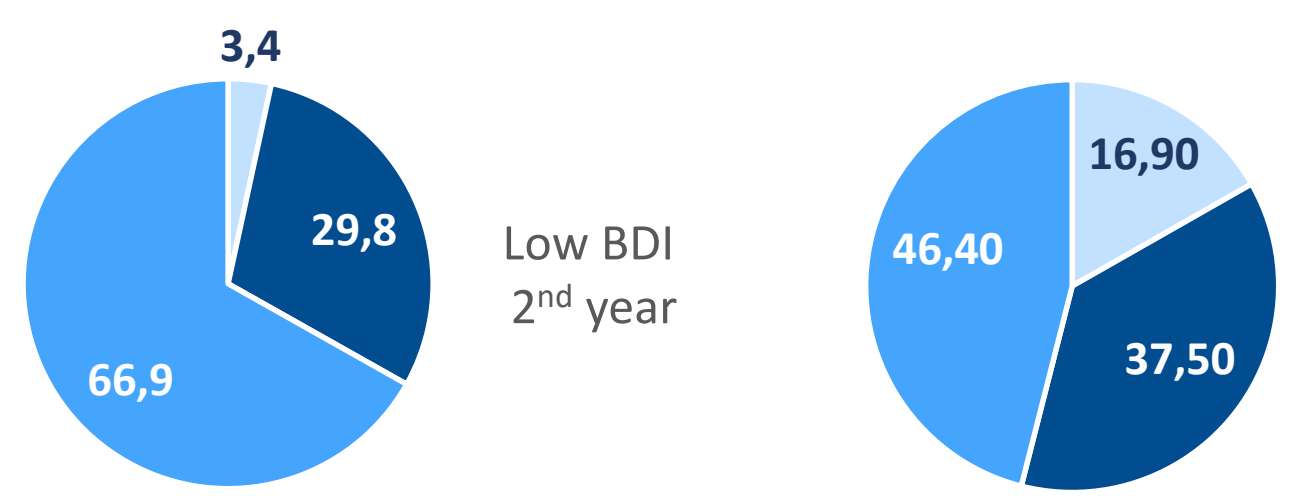

- repeaters

n completers

Increased BDI

$2^{\text {nd }}$ year

\section{Conclusion}

- There is a significant number of freshmen with higher depressive symptoms

- Students with a higher level of depressive symptoms are more prone to poor academic efficiency and higher drop-out, as well as low adjustment to college.

- It is important to early detect students with increased level of depressive symptoms and help them cope and facilitate their academic functioning.

\section{References}

Beiter, R., Nash, R., McCrady, M., Rhoades, D., Linscomb, M., Clarahan, M., \& Sammut, S. (2015). The prevalence and correlates of depression, anxiety, and stress in a sample of college students. Journal of Affective Disorders, 173, 90-96.

Eisenberg, D., Lipson, S. K., Ceglarek, P., Kern, A., \& Phillips, M. (2017). College Student Mental Health: The National Landscape. In D. Cimini, \& E.M. Rivero, (Eds.), Promoting Behavioral Health and Reducing Risk among College Students: A Comprehensive Approach. 